\title{
Downregulation of galectin-3 causes a decrease in uPAR levels and inhibits the proliferation, migration and invasion of hepatocellular carcinoma cells
}

\author{
DATONG ZHENG ${ }^{1,2}$, ZHENZHEN HU ${ }^{2}$, FAN HE$^{2}$, CAIJIE GAO ${ }^{2}$, LIJIAN XU ${ }^{2}$, \\ HAN ZOU $^{2}$, ZHIWEI WU ${ }^{3}$, XIUQIN JIANG ${ }^{2}$ and JIANJUN WANG ${ }^{1}$
}

\begin{abstract}
${ }^{1}$ Department of Biological Science and Technology and State Key Laboratory of Pharmaceutical Biotechnology, School of Life Sciences, Nanjing University, Nanjing, Jiangsu 210093; ${ }^{2}$ Research Center, The Second Hospital of Nanjing Medical University, Nanjing, Jiangsu 210011; ${ }^{3}$ Immunology and Reproductive Biology Laboratory and Jiangsu Key Laboratory of Molecular Medicine, Medical School, Nanjing University, Nanjing, Jiangsu 210093, P.R. China
\end{abstract}

Received February 19, 2014; Accepted April 4, 2014

DOI: $10.3892 /$ or.2014.3170

\begin{abstract}
Hepatocellular carcinoma (HCC) is the third most common cause of cancer-related mortality worldwide. Galectin-3 (Gal-3), a multifunctional $\beta$-galactoside-binding protein, is highly expressed and associated with the prognosis of HCC. However, the functions of Gal-3 in HCC cells are not fully understood. To address the function of Gal-3 in HCC cells, we used small interfering RNA (siRNA) to knock down Gal-3 expression in HepG2, an HCC cell line. We found that in vitro the silencing of Gal-3 decreased the proliferative activity, colony formation ability, migratory and invasive potential of HepG 2 cells. The silencing of Gal-3 significantly decreased the mRNA and protein levels of urokinase-type plasminogen activator receptor (UPAR) as well as UPAR's downstream signaling transduction pathway, including phosphorylation of AKT. Furthermore, the downregulation of Gal-3 by siRNA resulted in significantly decreased activity of the MEK/ERK signaling pathway, and the treatment of HepG2 cells with MEK/ERK inhibitor U0126 significantly reduced the mRNA and protein levels of uPAR. Taken together, our results suggest that Gal-3 modulates uPAR expression via the MEK/ERK pathway, and that Gal-3 may be a potential therapeutic target for the treatment of HCC.
\end{abstract}

Correspondence to: Dr Xiuqin Jiang, Research Center, The Second Hospital of Nanjing Medical University, 121 Jiangjiayuan, Nanjing 210011, P.R. China

E-mail: jiangxiuq@gmail.com

Dr Jianjun Wang, School of Life Sciences, Mailbox 426, 22 Hankou Road, Nanjing University, Nanjing 210093, P.R. China

E-mail: jjwang@nju.edu.cn

Key words: galectin-3, uPAR, migration, hepatocellular carcinoma cells, proliferation

\section{Introduction}

Hepatocellular carcinoma (HCC) is one of the most common malignant tumors, and its incidence is increasing (1-3). HCC is often diagnosed at advanced stages with local invasion and remote metastasis, making surgical resection and liver transplantation more difficult and less effective (4). Thus, studies are needed to identify this type of invasive cancer cell, and the signaling molecules that are specifically involved in tumor invasion.

Galectin-3 (Gal-3), a member of the carbohydrate-binding protein family, plays an important and multifaceted role in cancer pathogenesis (5-7). Bound to oncogenic Ras proteins, Gal-3 activates V-raf-1 murine leukemia viral oncogene homolog 1 (RAF1) and phosphatidylinositol 3-kinase (PI3K), which in turn induces aberrant gene expression and specific signaling cascades, resulting in the facilitation of tumor transformation $(7,8)$. Gal-3 has also been shown to modulate tumor invasion and metastasis by binding to integrins or by regulating their expression $(9,10)$. Additionally, Gal-3 secreted by tumors induces angiogenesis $(9,11,12)$. These characteristics have made therapeutic targeting of Gal-3 an attractive concept in cancer biology (13-18). In HCC, Gal-3 overexpression is involved in tumor progression and is related to prognosis (19). However, the underlying molecular mechanism of Gal-3 in the development of HCC remains unclear.

The urokinase plasminogen activator receptor (UPAR), a multidomain glycoprotein tethered to the cell membrane with a glycosylphosphotidylinositol (GPI) anchor, is elevated in many human cancers, and is frequently associated with poor prognosis (20-22). uPAR regulates proteolysis by binding the extracellular protease urokinase-type plasminogen activator (uPA) and also activates many intracellular signaling pathways via interactions with membrane-bound integrins $(23,24)$. Coordination of extracellular matrix (ECM) proteolysis and cell signaling by uPAR underlies its important function in cell migration, proliferation and survival. These attributes make UPAR an attractive therapeutic target in cancer treatment (25-27). 
Table I. siRNA sequences.

\begin{tabular}{llr}
\hline Name & Sense/antisense siRNA (5'-3') & Target \\
\hline Gal-3-homo-422 & GCC ACU GAU UGU GCC UUA UTT/ & $424-442$ \\
Gal-3-homo-568 & AUA AGG CAC AAU CAG UGG CTT & $570-588$ \\
Gal-3-homo-746 & CAC GCU UCA AUG AGA ACA ATT/ & $748-766$ \\
Negative control & UUG UUC UCA UUG AAG CGU GTT & \\
& GUA CAA UCA UCG GGU UAA ATT/ & \\
& UUU AAC CCG AUG AUU GUA CTT & \\
& UUC UCC GAA CGU GUC ACG UTT/ & \\
\end{tabular}

Table II. Primers for RT-PCR.

\begin{tabular}{ll}
\hline Primers & \multicolumn{1}{c}{ Sequences (5'-3') } \\
\hline Gal-3-F & ATGGCAGACAATTTTTCGCTCCA \\
Gal-3-R & TATCATGGTATATGAAGCACTGG \\
uPAR-F & TTACCGAGGTTGTGTGTGGG \\
uPAR-R & GGGCATGTTGGCACATTGAG \\
GAPDH-F & TGAACGGGAAGCTCACTGG \\
GAPDH-R & TCCACCACCCTGTTGCTGTA \\
\hline
\end{tabular}

Previous studies have shown that induction of UPAR in cancer is ERK-dependent (28-30). In human hepatocarcinoma cells, ERK-dependent uPAR expression is required for motility of tumor cells (31). Gal-3 also promotes cancer progression by modulating the activity of ERK $(32,33)$. Therefore, it is possible that in HCC, Gal-3 regulates tumor development via modulation of uPAR expression, as the overexpression of Gal-3 and UPAR has been reported in $\operatorname{HCC}(19,34)$. To investigate whether Gal-3 is related to UPAR in the development of HCC, we knocked down the expression of Gal-3 in HepG2 cells and assayed uPAR expression, and the proliferation, migration and invasion of the cells.

\section{Materials and methods}

Cell culture. HepG2 and Huh7 cells were purchased from the Chinese Academy of Sciences Cell Bank (Shanghai, China). Cells were maintained at $37^{\circ} \mathrm{C}$ in Minimum Essential Medium (MEM) (Invitrogen, USA) supplemented with $10 \%$ fetal bovine serum, $100 \mathrm{U} / \mathrm{ml}$ penicillin and $100 \mathrm{U} / \mathrm{ml}$ streptomycin under humidified conditions containing $95 \%$ air and $5 \% \mathrm{CO}_{2}$.

siRNA transfection. siRNA was designed and synthesized by the Shanghai GenePharma Co., Ltd. according to the galectin-3 gene sequence (GenBank accession no.NM 002306.3) as listed in Table I. Transfection was carried out using Lipofectamine 2000 (Invitrogen, Carlsbad,CA, USA) following the manufacturer's instructions. The siRNA-transfected cells were analyzed by RT-PCR and western blotting.
Reverse transcription polymerase-chain reaction (RT-PCR). Total RNAs were isolated with the TRIzol reagent according to the manufacturer's protocol (Invitrogen). cDNA was then synthesized using the SuperScript First Strand Synthesis System (Invitrogen) and amplified by polymerase chain reaction (PCR). The primer sequences are listed in Table II. PCR conditions were as follows: $95^{\circ} \mathrm{C}$ for $3 \mathrm{~min}$, followed by 28 cycles of $95^{\circ} \mathrm{C}$ for $30 \mathrm{sec}, 55^{\circ} \mathrm{C}$ for $30 \mathrm{sec}$, and $72^{\circ} \mathrm{C}$ for $1 \mathrm{~min}$, the final extension was at $72^{\circ} \mathrm{C}$ for $6 \mathrm{~min}$. The PCR products were electrophoresed on $1 \%$ agarose.

Western blot analysis. All cells were harvested after the indicated control and Gal-3 siRNA treatments. Protein was

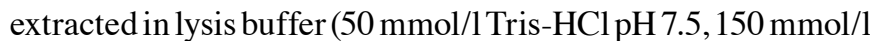
$\mathrm{NaCl}, 1 \% \mathrm{NP}-40,0.5 \%$ sodium deoxycholate, $0.1 \%$ SDS and protease inhibitors). Fifty micrograms of protein was loaded on a $10 \%$ SDS-PAGE gel, followed by protein separation and electroblotting onto a polyvinylidene difluoride membrane. The membrane was labeled with the following primary antibodies: anti-galectin-3 (Abcam, USA), goat anti-uPAR (Santa Cruz Biotechnology, USA), anti-GAPDH antibody (Chemicon, USA), anti-phospho-ERK, anti-ERK, anti-phospho-AKT and anti-AKT (Cell Signaling Technology, USA). HRP-conjugated secondary antibodies were incubated in 5\% BSA in TBST buffer for $1.5 \mathrm{~h}$ at room temperature. Immunoreactivity was detected using an enhanced chemiluminescence detection system (Pierce, USA).

Colony-formation assay. Control and Gal-3 siRNA-treated HepG2 cells were plated in duplicate on 6-well culture plates at a density of 3,000 cells/well. Culture medium was subsequently changed every 3 days. After 2 weeks, the colonies were fixed and stained with $2 \%$ crystal violet, and the number of colonies that consisted of more than 10 cells were counted.

Cell proliferation assay. Cell proliferation was measured by an MTT tetrazolium assay. HepG 2 cells $\left(2.5 \times 10^{3}\right.$ cells/well $)$ transfected with either control or Gal-3 siRNA were cultured in 96-well microtiter plates in a total volume of $100 \mu \mathrm{l} /$ well for 3 days. Each day, $10 \mu \mathrm{l}$ of MTT $(5 \mathrm{mg} / \mathrm{ml})$ in $100 \mu \mathrm{l}$ of basic MEM per well were added and incubated for $4 \mathrm{~h}$. After removing MTT, $150 \mu 1$ of dimethyl sulfoxide (DMSO) was added and mixed vigorously. Absorbance was measured 
A
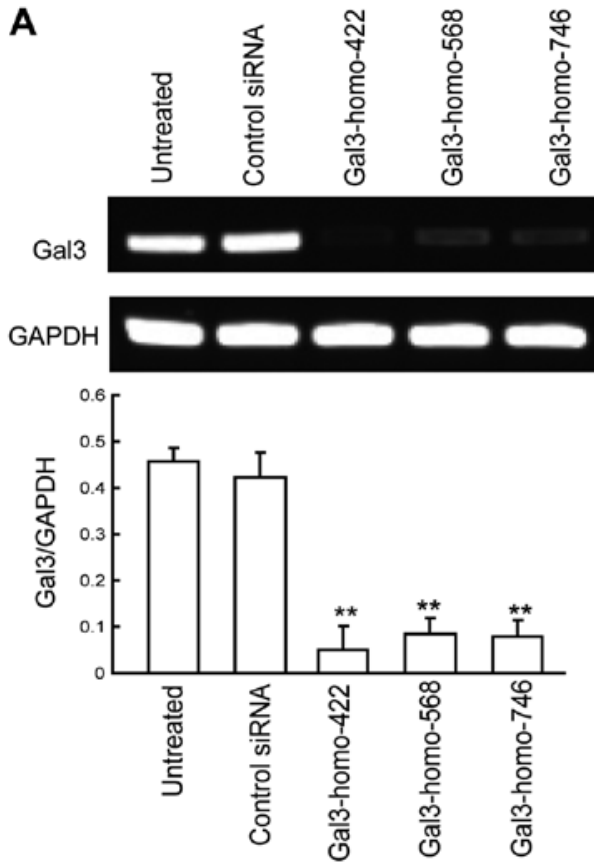

B

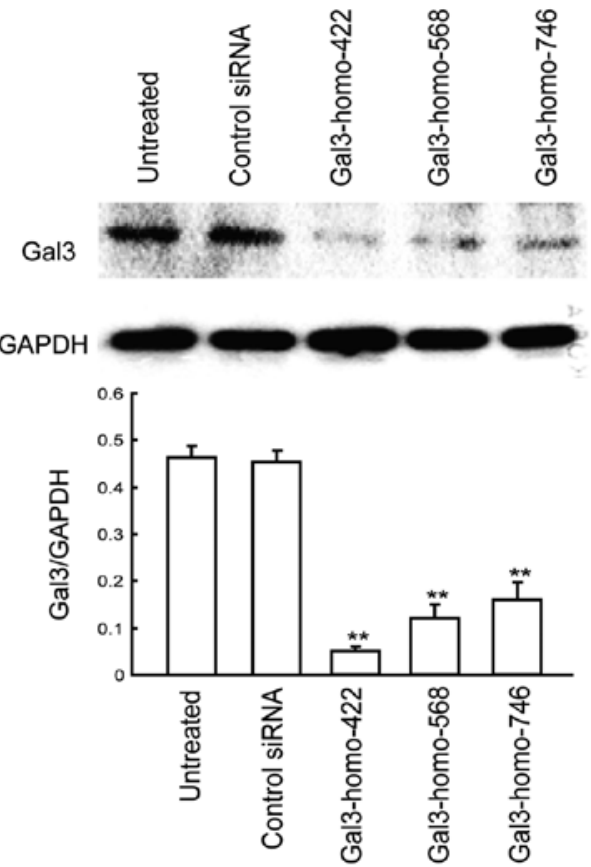

Figure 1. Downregulation of Gal-3 expression by siRNA in HepG2 cells. (A) Cells were transfected with the appropriate siRNA oligonucleotides as described in Materials and methods. After $72 \mathrm{~h}$, the expression of Gal-3 mRNA was analyzed using RT-PCR. (B) Gal-3 expression in HepG2 cells after transfection with the appropriate siRNA oligonucleotides was measured by western blot analysis. ${ }^{* *} \mathrm{P}<0.01$ vs. control siRNA. GAPDH served as a loading control.

at $490 \mathrm{~nm}$ using the Emax-precision microtiter plate reader (Molecular Devices, USA).

In vitro migration and invasion assays. Cell motility was measured using 48-well BioCoat Cell Culture Inserts (BD Biosciences, USA). Fibronectin $(5 \mathrm{mg} / \mathrm{ml})$ in serum-free medium was placed in each lower chamber, which was separated from the upper chamber by a membrane with $8-\mu \mathrm{m}$ pores. A single-cell suspension of HepG2 cells $\left(5 \times 10^{4}\right)$ in serum-free medium was placed in each upper chamber. After incubation for $24 \mathrm{~h}$ at $37^{\circ} \mathrm{C}$, the cells were fixed with methanol and stained with $0.1 \%$ crystal violet. The cells on the upper surface of the filter were wiped off with a cotton swab, and the number of cells that migrated out to the lower surface of the membranes were counted in 5 randomly selected fields. Invasion assays were performed with Matrigel-coated chambers from the BioCoat Matrigel Invasion Chamber kit (BD Biosciences) using the same method as described above for the migration assays.

Wound healing assay. Cells were seeded in 96-well plates and allowed to grow until $70 \%$ confluency. The cells were pretreated with mitomycin $\mathrm{C}$, which inhibits cell division, so that the difference in motility was not affected by the difference in cell proliferation rates. The cells were treated as above and wounding was performed by scraping through the cell monolayer with a $10-\mu 1$ pipette tip. After being washed with PBS, images were captured immediately after scratching for various periods of time in the same marked location of the plate. All experiments were performed in triplicate.

Statistical analysis. Experiments were carried out at least in triplicate, and the results were expressed as mean \pm SD. The data were analyzed using the Student's t-test. Statistical significance was considered at $\mathrm{P}<0.05$.

\section{Results}

Downregulation of Gal-3 in HepG2 cells by siRNA. To investigate the role of Gal-3 in HCC cells, endogenous Gal-3 expression was inhibited by siRNA in HepG2 cells. RT-PCR and western blot analysis were used to evaluate the ability of different Gal-3 siRNAs to silence Gal-3 expression in vitro. We chose three Gal-3 siRNA sequences (Gal-3-homo-422, Gal-3-homo-568, and Gal-3-homo-746) based on previous research. The suppression rate of Gal-3 mRNA expression was separately reached at $89.17,61.61$ and $82.56 \%$, as measured by RT-PCR (Fig. 1A). The suppression rate of Gal-3 protein was separately reached at $89.26,74.51$ and $65.59 \%$ for each Gal-3 siRNA, as measured by western blot analysis (Fig. 1B). The results indicated that Gal-3-homo-422 was the most effective silencer. Thus, Gal-3-homo-422 was chosen in the subsequence experiments for gene knockdown. No differences were observed in regards to Gal-3 mRNA or protein levels in HepG2 cells which were transfected with control siRNA.

Downregulation of Gal-3 inhibits the proliferation and colony formation of HepG 2 cells. The roles of Gal-3 downregulation in cell proliferation and tumorigenesis were evaluated by MTT and colony formation assays, respectively. The HepG2 cells knocked down for Gal-3 displayed significantly altered growth profiles when compared to the control siRNA-transfected cells (Fig. 2A). While the growth curves of Gal-3-knockdown cells reached a plateau at $24 \mathrm{~h}$ following seeding, the control siRNA transfectants displayed a steadily increasing population level. Total cell number became significantly different $(\mathrm{P}<0.05)$ 
A

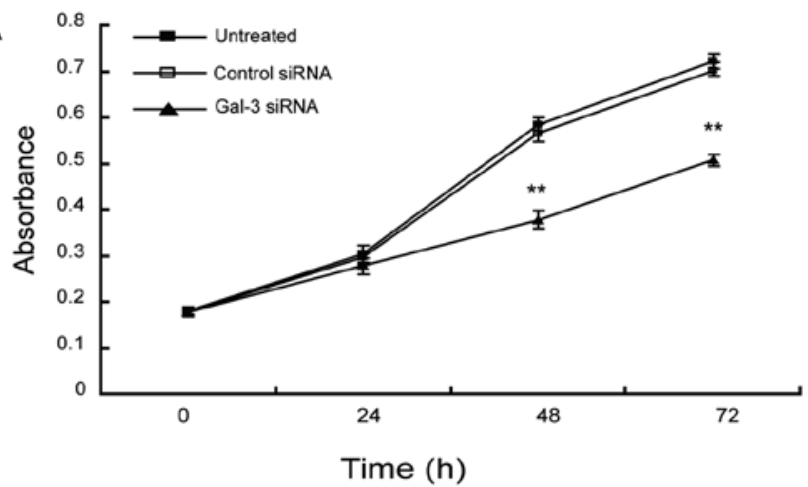

B
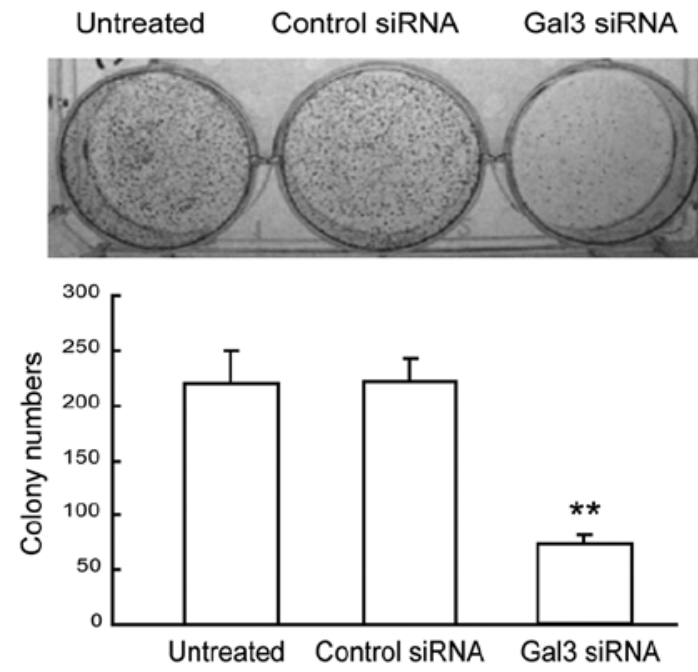

Figure 2. Effects of Gal-3 downregulation on the proliferation and colony formation of HepG2 cells. (A) Proliferation assay. HepG2 cells transfected with control or Gal-3 siRNA were cultured in 96-well microplates. The indicated reagent was injected after $0,24,48$, or $72 \mathrm{~h}$ of culture after which the cells were incubated for an additional $4 \mathrm{~h}$. The absorbance was detected using a microplate reader. (B) Colony formation assay. HepG2 cells were transfected with control or Gal-3 siRNA, and tumorigenicity in vitro was analyzed by colony formation assay. The accompanying graph summarizes the colonyforming capacities of the various transfectants. ${ }^{* *} \mathrm{P}<0.01$ vs. control siRNA.

between the two populations at $48 \mathrm{~h}$. Additionally, Gal-3knockdown HepG2 cells displayed a significantly decreased capacity to form colonies ( $\mathrm{P}<0.05$, Fig. $2 \mathrm{~B}$ ). While untransfected and control siRNA-transfected HepG2 cells were able to form similar numbers of colonies after 14 days $(220 \pm 29.0$ and $222 \pm 20.1$, respectively), Gal-3-knockdown HepG2 cells were only able to form an average of $73.7( \pm 8.5)$ colonies per well, representing a $67 \%$ reduction in colony-forming capacity. These data indicate that Gal-3 plays an important role in the proliferation and colony formation of HepG2 cells.

Downregulation of Gal-3 reduces cell migration and invasion of HepG2 cells. To investigate the role of Gal-3 in HepG2 cell migratory and invasive processes, we performed cell migration, wound healing and invasion assays using HepG2 cells transfected with control or Gal-3 siRNA. As shown in Fig. 3A, Gal-3 downregulation induced an $\sim 2$-fold decrease in the migration of HepG2 cells according to the chamber-based assays $(\mathrm{P}<0.01)$. Moreover, wound-healing assays confirmed the inhibitory effect of Gal-3 downregulation on cell migra-
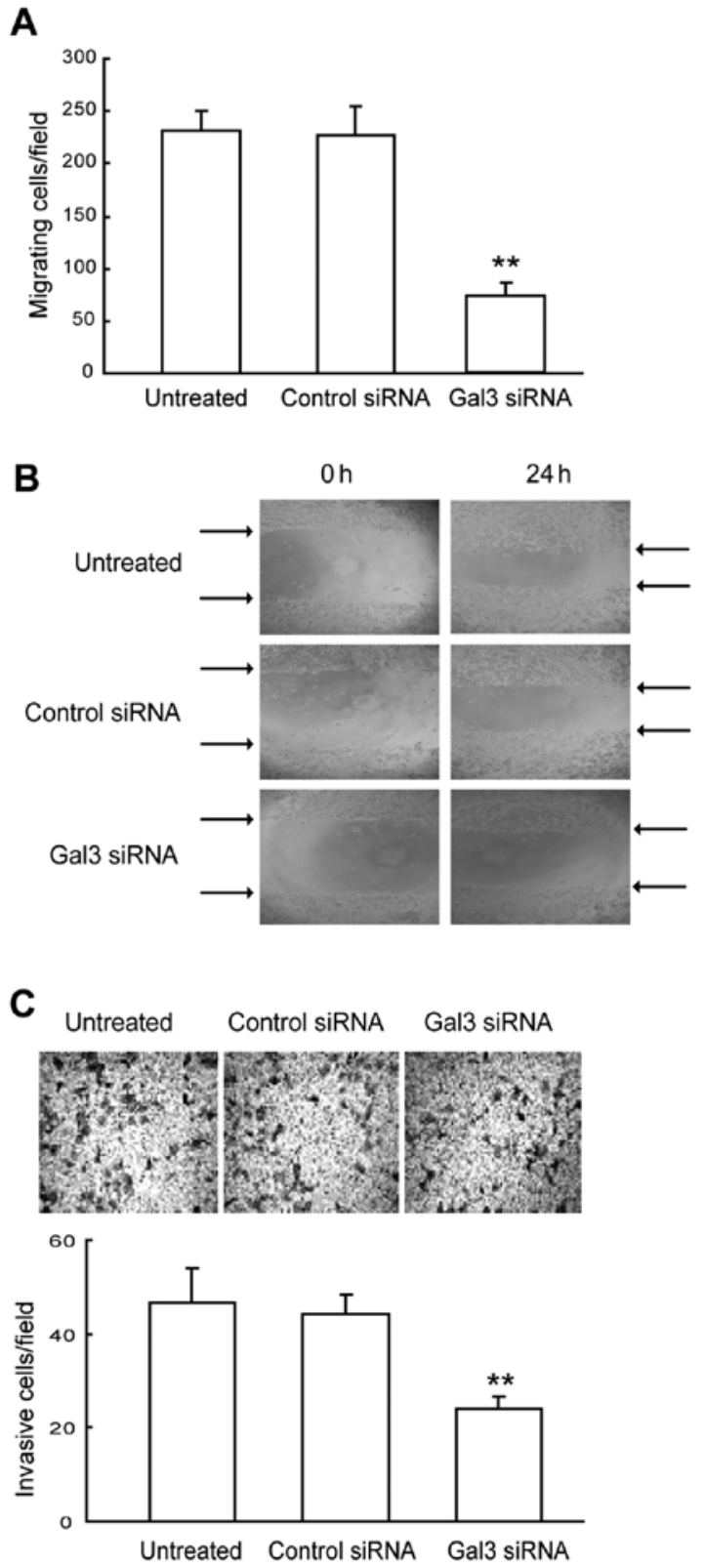

Figure 3. Effects of Gal-3 downregulation on the migration and invasion of HepG2 cells. (A) Migration assay. After transfection with either control or Gal-3 siRNA for $48 \mathrm{~h}$ (or cells were left untreated), the HepG2 cells were tested for migration using a modified Boyden chamber method and were evaluated on the basis of the mean values from five fields of view at $\times 200$ magnification for each treatment. (B) Representative images of the woundhealing experimental results in HepG2 cells. HepG2 cells transfected with either control or Gal-3 siRNA were wounded and maintained for $48 \mathrm{~h}$ in DMEM with $10 \%$ FBS. Arrows point to the edges of the wounds. Wound closure time after $24 \mathrm{~h}$ was slower in cells transfected with Gal-3 siRNA than in those transfected with control siRNA. (C) Invasion assay. Cells that were invaded through the pores on the lower surface of Matrigel-coated chambers are shown. Invaded cells transfected with control or Gal-3 siRNA were evaluated on the basis of the mean values from five fields of view at x200 magnification for each treatment. Data for each treatment are represented as the mean $\pm \mathrm{SD} .{ }^{* *} \mathrm{P}<0.01$ vs. control siRNA.

tion. We found that the time required for wound closure of the Gal-3-knockdown HepG2 cells was significantly longer than the time required for the corresponding control cells (Fig. 3B). In keeping with the migratory patterns, Gal-3-knockdown cells displayed a significantly reduced ability $(\mathrm{P}<0.01)$ to invade 
A

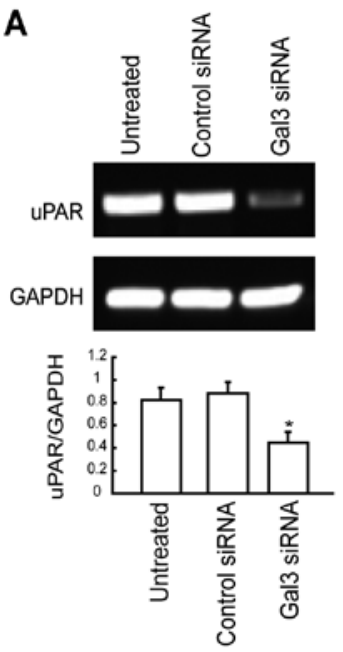

B

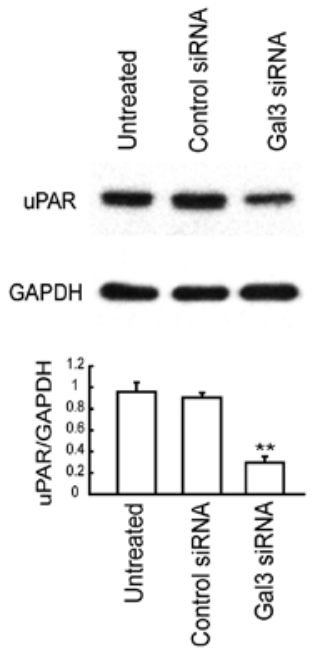

C
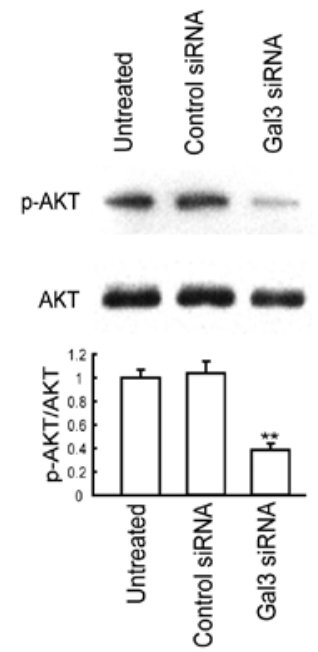

D

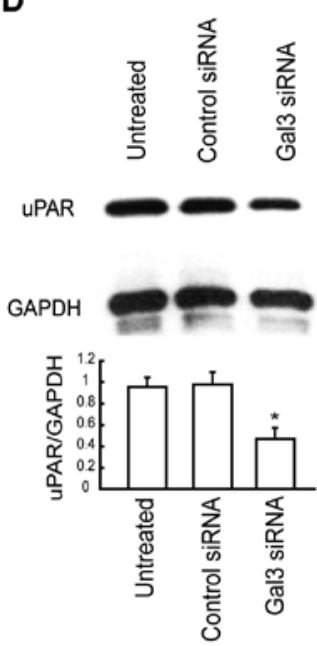

E

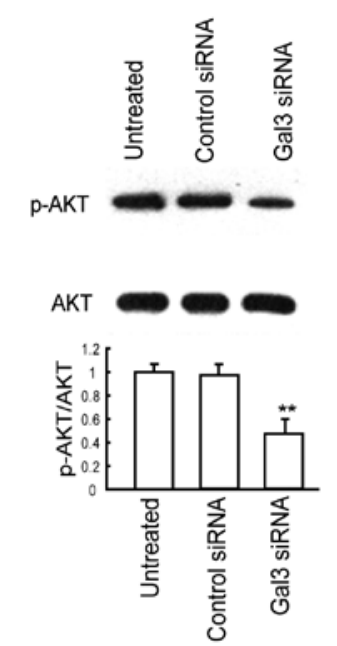

Figure 4. Effects of Gal-3 downregulation on uPAR expression. (A and B) Expression of uPAR in Gal-3-knockdown HepG2 cells. The HepG2 cells were transfected with control or Gal-3 siRNA for $72 \mathrm{~h}$, or left untreated. The cells were harvested, and mRNA and protein levels were detected by RT-PCR and western blot analysis. (C) The effect of Gal-3 downregulation on AKT expression. Total and phosphorylated p-AKT expression levels in the control or Gal-3 siRNA-transfected HepG2 cells were detected by western blot analysis. (D and E) Expression of uPAR and p-AKT in Gal-3-knockdown Huh7 cells. After the Huh7 cells were transfected by control or Gal-3 siRNA for $72 \mathrm{~h}$, or were left untreated, they were harvested and levels of uPAR and p-AKT were detected by western blotting. $\mathrm{P}<0.05,{ }^{* *} \mathrm{P}<0.01$ vs. control siRNA.

and migrate through a Matrigel barrier relative to the control siRNA-treated cells (Fig. 3C). Collectively, these results indicate that Gal-3 plays an important role in the migration and invasion of HepG2 cells.

Downregulation of Gal-3 decreases $U P A R$ expression. To explore the underlying mechanism of reduced cell proliferation, migration and invasion by Gal-3 downregulation, expression of UPAR in the total cell lysate was examined by RT-PCR and western blot analysis. As shown in Fig. 4A and $\mathrm{B}, \mathrm{mRNA}$ and protein levels of UPAR were significantly lower in the Gal-3 siRNA-treated HepG2 cells than levels in the corresponding controls. We also sought to determine whether established downstream effectors of uPAR are similarly disrupted. Fig. 4C shows that the p-AKT levels were also greatly reduced in the Gal-3-knockdown HepG2 cells, while total Akt levels remained unchanged and comparable to those observed in the control cells. Similar results were obtained in another HCC cell line, Huh7 (Fig. 4D and E). Taken together, these results suggest that downregulation of Gal-3 decreases uPAR expression and its downstream signaling.

ERK is activated by Gal-3 and its activation is correlated with UPAR expression. According to previous findings, Gal-3 regulates the activation of $\operatorname{ERK}(32,33)$. In the present study, we determined the activity of ERK in Gal-3-knockdown HepG2 cells. We found markedly decreased phosphorylation of ERK in the Gal-3-knockdown HepG2 cells (Fig. 5A). As ERK activation is known to induce UPAR expression in a variety of cancer cells (28-30), we determined whether UPAR expression is positively regulated by MEK/ERK activity in HepG2 cells. We treated HepG2 cells for $12 \mathrm{~h}$ with the synthetic MEK inhibitor U0126 (10 $\mu \mathrm{M})$. RT-PCR data revealed decreased uPAR expression in U0126-treated cells compared with that in the control cells (Fig. 5B). uPAR expression was reconfirmed at the protein level in the U0126-treated cells by western blotting 

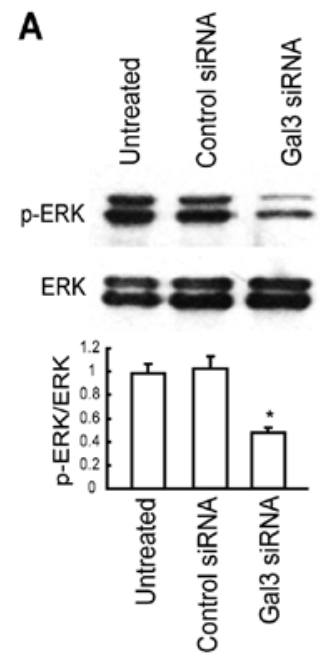

B
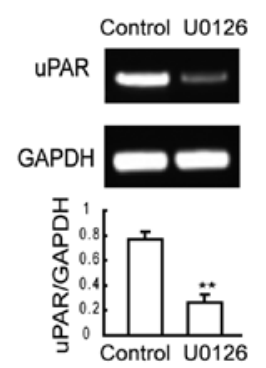

C

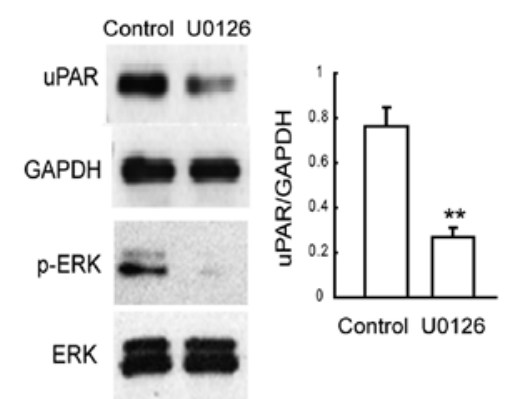

Figure 5. Effect of Gal-3 downregulation on ERK activation and decreased uPAR expression following inhibition of ERK. (A) The effect of Gal-3 downregulation on ERK expression. The total and phosphorylated p-ERK expression levels in control or Gal-3 siRNA-transfected cells were detected by western blot analysis. (B and C) The effect of MEK inhibitor U0126 on uPAR expression in HepG2 cells. Cells were treated with $10 \mu$ M U0126 for 12 h, then RNA and protein were collected for RT-PCR or western blot analysis, respectively. ${ }^{*} \mathrm{P}<0.05,{ }^{* *} \mathrm{P}<0.01$ vs. control siRNA.

(Fig. 5C). Taken together, these results indicate that downregulation of Gal-3 in HepG2 cells reduced uPAR expression via the MEK/ERK pathway.

\section{Discussion}

Galectin-3 (Gal-3) is a member of the $\beta$-gal-binding galectin family that exhibits pleiotropic biological functions. Gal-3 is reported to be upregulated in many tumors and is involved in several important processes, including cell-to-cell adhesion, cell-to-extracellular matrix (ECM) interactions, cell growth, differentiation, adhesion, migration, angiogenesis, malignant transformation, apoptosis and cancer drug resistance $(5,6,9$, $10,12,35,36)$. The expression of Gal-3 is detected in $\sim 65 \%$ of $\mathrm{HCC}$, and is highly correlated with progression and prognosis of HCC (19). However, the actual biological functions of Gal-3 in HCC have not yet been well described. The present study was designed to address this issue using HepG2, a hepatocellular liver carcinoma cell line that expresses high levels of Gal-3.

In the present study, we knocked down expression of Gal-3 in HCC cells with small interfering RNA (siRNA), and demonstrated that siRNA targeting of Gal-3 in the HepG2 cell line led to the efficient and specific inhibition of endogenous Gal-3 mRNA and protein in vitro. We found that downregulation of Gal-3 in HepG2 cells contributed to reduced cell migration and cell invasion. This suggests that Gal-3 is closely associated with the metastatic events of HepG2 cells. Our data are consistent with observations in the growth of many different types of human cancers such as breast, colon, and brain tumors $(32,37,38)$. Previous research has implicated Gal-3 in the modulation of tumor cell growth and tumorigenic phenotype of cancer cells $(39,40)$. We found that Gal-3-knockdown HepG2 cells displayed decreased cell proliferation and colony formation efficiency. Coupled with the observations in cell migration and cell invasion, we postulate that Gal-3 expression is associated with migration, invasion, proliferation and the tumorigenicity of HepG2 cells. Our finding is different from a recent publication by Kobayashi et al (41). They reported that transient gene silencing of Gal-3 suppresses pancreatic cancer cell migration and invasion, but failed to affect proliferation. We believe that the observed discrepancy could be due to the different cell systems.

Our findings also concern the key factors and signaling pathways mediated by Gal-3, which are associated with HCC progression. A number of recent studies have demonstrated a correlation between Gal-3 and ERK in several cancer cell lines and have implicated this association in cancer progression $(33,42,43)$. In the present study, we examined whether Gal-3 downregulation affects ERK expression in HepG2 cells. We found that Gal-3 siRNA-transfected cells had markedly reduced phosphrylation of ERK compared to their corresponding control cells, indicating that Gal-3 regulates migration, invasion, proliferation and tumorigenicity of HepG2 cells through the ERK pathway. Previous research has shown that Gal-3 binds Ras and enhances Ras activity and downstream signaling including phospshorylation of ERK, thereby inducing cell proliferation and invasion in pancreatic cancer (33). Therefore, based on our study, we suggest that the decreased phosphorylation of ERK observed in Gal-3 siRNAtransfected HepG2 cells may be due to decreased Ras activity. Future experiments are needed to explore this issue.

Recent studies have demonstrated that Gal-3 interacts with many signaling pathways, such as the Wnt/ $\beta$-catenin signaling pathway $(9,33,44-47)$. However, its interaction with the UPAR pathway has not yet been reported. UPAR is a multifunctional protein which is involved in several cellular processes such as cell proliferation, migration, angiogenesis and invasion (48). Studies have demonstrated that expression of UPAR is increased in HCC, and is related to the invasiveness, metastasis and prognosis of $\operatorname{HCC}(19,49)$. In this study, we found that Gal-3 silencing triggered the downregulation of uPAR in HepG2 and Huh7 cells. In addition, Gal-3 silencing significantly inhibited the phosphorylation of AKT. The activation of PI3K/AKT signaling by uPAR has been well 
documented in cancer research (23). It is known that the activated PI3K/AKT pathway directly modulates cell growth and movement behavior $(23,50)$. Therefore, our results suggest that Gal-3 modulates the PI3K/AKT pathway via uPAR, thereby affecting cell proliferation, migration and invasion $(23,50)$.

In addition, UPAR induction has been well documented in several types of cancers by ERK (28-30). A study by Bessard et al (31) revealed that MEK/ERK-dependent UPAR expression is required for motility in human hepatocarcinoma cells. We found that MEK inhibitor significantly inhibited UPAR expression, indicating that the induction of uPAR in HepG2 cells is MEK/ERK-dependent. Therefore, we conclude that the decreased UPAR expression observed in the present study might be due to decreased ERK activity induced by Gal-3 downregulation.

In conclusion, our study revealed that Gal-3 regulates the level of UPAR in HCC cells. Gal-3 mediates cell proliferation, migration and invasion by activating ERK, which regulates uPAR expression. Understanding the underlying mechanisms may provide new strategies for HCC treatment. RNA interference of Gal-3 and uPAR expression could be considered as an effective anti-HCC strategy.

\section{Acknowledgements}

This research was supported by grants from the Health Department of Jiangsu (H200824), the Program for Advanced Talents within Six Industries of Jiangsu to D.Z. (07-B-023), and the Research Program funded by Nanjing Medical University to Z.H. (2012NJMU088).

\section{References}

1. El-Serag HB, Mason AC and Key C: Trends in survival of patients with hepatocellular carcinoma between 1977 and 1996 in the United States. Hepatology 33: 62-65, 2001.

2. Altekruse SF, McGlynn KA and Reichman ME: Hepatocellular carcinoma incidence, mortality, and survival trends in the United States from 1975 to 2005. J Clin Oncol 27: 1485-1491, 2009.

3. Jemal A, Bray F, Center MM, et al: Global cancer statistics. CA Cancer J Clin 61: 69-90, 2011.

4. Carr BI: Hepatocellular carcinoma: current management and future trends. Gastroenterology 127: S218-S224, 2004.

5. Takenaka Y, Fukumori T and Raz A: Galectin-3 and metastasis. Glycoconj J 19: 543-549, 2004.

6. Radosavljevic G, Volarevic V, Jovanovic I, et al: The roles of Galectin-3 in autoimmunity and tumor progression. Immunol Res 52: 100-110, 2012.

7. Saussez S, Camby I, Toubeau G and Kiss R: Galectins as modulators of tumor progression in head and neck squamous cell carcinomas. Head Neck 29: 874-884, 2007.

8. McCubrey JA, Steelman LS, Abrams SL, et al: Roles of the RAF/ MEK/ERK and PI3K/PTEN/AKT pathways in malignant transformation and drug resistance. Adv Enzyme Regul 46: 249-279, 2006.

9. Wesley UV,Vemuganti R, Ayvaci ER and Dempsey RJ: Galectin-3 enhances angiogenic and migratory potential of microglial cells via modulation of integrin linked kinase signaling. Brain Res 1496: 1-9, 2013.

10. Friedrichs J, Manninen A, Muller DJ and Helenius J: Galectin-3 regulates integrin alpha2beta1-mediated adhesion to collagen-I and -IV. J Biol Chem 283: 32264-32272, 2008.

11. Piccolo E, Tinari N, Semeraro D, et al: LGALS3BP, lectin galactoside-binding soluble 3 binding protein, induces vascular endothelial growth factor in human breast cancer cells and promotes angiogenesis. J Mol Med 91: 83-94, 2013.

12. Nangia-Makker P, Wang Y, Raz T, et al: Cleavage of galectin-3 by matrix metalloproteases induces angiogenesis in breast cancer. Int J Cancer 127: 2530-2541, 2010.
13. Rossi ED, Straccia P, Palumbo M, et al: Diagnostic and prognostic role of HBME-1, galectin-3, and beta-catenin in poorly differentiated and anaplastic thyroid carcinomas. Appl Immunohistochem Mol Morphol 21: 237-241, 2013.

14. Yamaki S, Fujii T, Yajima R, et al: Clinicopathological significance of decreased galectin-3 expression and the long-term prognosis in patients with breast cancer. Surg Today 43: 901-905, 2013.

15. Cui W, Sang W, Zheng S, et al: Usefulness of cytokeratin-19, galectin-3, and Hector Battifora mesothelial-1 in the diagnosis of benign and malignant thyroid nodules. Clin Lab 58: 673-680, 2012.

16. Blanquart C, Gueugnon F, Nguyen JM, et al: CCL2, galectin-3, and SMRP combination improves the diagnosis of mesothelioma in pleural effusions. J Thorac Oncol 7: 883-889, 2012.

17. Paunovic I, Isic T, Havelka M, et al: Combined immunohistochemistry for thyroid peroxidase, galectin-3, CK19 and HBME-1 in differential diagnosis of thyroid tumors. APMIS 120: 368-379, 2012.

18. Chiu CG, Strugnell SS, Griffith OL, et al: Diagnostic utility of galectin-3 in thyroid cancer. Am J Pathol 176: 2067-2081, 2010.

19. Matsuda Y, Yamagiwa Y, Fukushima K, Ueno Y and Shimosegawa T: Expression of galectin-3 involved in prognosis of patients with hepatocellular carcinoma. Hepatol Res 38: 1098$1111,2008$.

20. Baldini E, Sorrenti S, D'Armiento E, et al: The urokinase plasminogen activating system in thyroid cancer: clinical implications. G Chir 33: 305-310, 2012.

21. Laerum OD, Ovrebo K, Skarstein A, et al: Prognosis in adenocarcinomas of lower oesophagus, gastro-oesophageal junction and cardia evaluated by uPAR-immunohistochemistry. Int J Cancer 131: 558-569, 2012.

22. Jacobsen B and Ploug M: The urokinase receptor and its structural homologue $\mathrm{C} 4.4 \mathrm{~A}$ in human cancer: expression, prognosis and pharmacological inhibition. Curr Med Chem 15: 2559-2573, 2008

23. Smith HW and Marshall CJ: Regulation of cell signalling by uPAR. Nat Rev Mol Cell Biol 11: 23-36, 2010.

24. Dass K, Ahmad A, Azmi AS, Sarkar SH and Sarkar FH: Evolving role of uPA/uPAR system in human cancers. Cancer Treat Rev 34: 122-136, 2008.

25. Mani T, Wang F, Knabe WE, et al: Small-molecule inhibition of the UPAR.uPA interaction: Synthesis, biochemical, cellular, in vivo pharmacokinetics and efficacy studies in breast cancer metastasis. Bioorg Med Chem 21: 2145-2155, 2013.

26. Lebeau AM, Duriseti S, Murphy ST, et al: Targeting uPAR with antagonistic recombinant human antibodies in aggressive breast cancer. Cancer Res 73: 2070-2081, 2013.

27. Soydinc HO, Duranyildiz D, Guney N, Derin D and Yasasever V: Utility of serum and urine UPAR levels for diagnosis of breast cancer. Asian Pac J Cancer Prev 13: 2887-2889, 2012.

28. Park JS, Park JH, Khoi PN, Joo YE and Jung YD: MSP-induced RON activation upregulates uPAR expression and cell invasiveness via MAPK, AP-1 and NF-kappaB signals in gastric cancer cells. Carcinogenesis 32: 175-181, 2011.

29. Baek MK, Park JS, Park JH, et al: Lithocholic acid upregulates uPAR and cell invasiveness via MAPK and AP-1 signaling in colon cancer cells. Cancer Lett 290: 123-128, 2010.

30. Yoon SY, Lee YJ, Seo JH, et al: uPAR expression under hypoxic conditions depends on iNOS modulated ERK phosphorylation in the MDA-MB-231 breast carcinoma cell line. Cell Res 16: 75-81, 2006.

31. Bessard A, Fremin C, Ezan F, Coutant A and Baffet G: MEK/ ERK-dependent UPAR expression is required for motility via phosphorylation of P70S6K in human hepatocarcinoma cells. J Cell Physiol 212: 526-536, 2007.

32. Wu KL, Huang EY, Jhu EW, et al: Overexpression of galectin-3 enhances migration of colon cancer cells related to activation of the K-Ras-Raf-Erk1/2 pathway. J Gastroenterol 48: 350-359, 2013.

33. Song S, Ji B, Ramachandran V, et al: Overexpressed galectin-3 in pancreatic cancer induces cell proliferation and invasion by binding Ras and activating Ras signaling. PLoS One 7: e42699, 2012.

34. Weng CJ, Tsai CM, Chen YC, et al: Evaluation of the association of urokinase plasminogen activator system gene polymorphisms with susceptibility and pathological development of hepatocellular carcinoma. Ann Surg Oncol 17: 3394-3401, 2010.

35. Nangia-Makker P, Nakahara S, Hogan V and Raz A: Galectin-3 in apoptosis, a novel therapeutic target. J Bioenerg Biomembr 39: 79-84, 2007. 
36. Fukumori T, Kanayama HO and Raz A: The role of galectin-3 in cancer drug resistance. Drug Resist Updat 10: 101-108, 2007.

37. Song YK, Billiar TR and Lee YJ: Role of galectin-3 in breast cancer metastasis: involvement of nitric oxide. Am J Pathol 160: 1069-1075, 2002.

38. Bresalier RS, Yan PS, Byrd JC, Lotan R and Raz A: Expression of the endogenous galactose-binding protein galectin-3 correlates with the malignant potential of tumors in the central nervous system. Cancer 80: 776-787, 1997.

39. Cvejic DS, Savin SB, Petrovic IM, et al: Galectin-3 expression in papillary thyroid carcinoma: relation to histomorphologic growth pattern, lymph node metastasis, extrathyroid invasion, and tumor size. Head Neck 27: 1049-1055, 2005.

40. John CM, Leffler H, Kahl-Knutsson B, Svensson I and Jarvis GA Truncated galectin-3 inhibits tumor growth and metastasis in orthotopic nude mouse model of human breast cancer. Clin Cancer Res 9: 2374-2383, 2003.

41. Kobayashi T, Shimura T, Yajima T, et al: Transient gene silencing of galectin-3 suppresses pancreatic cancer cell migration and invasion through degradation of beta-catenin. Int J Cancer 129: 2775-2786, 2011.

42. Alge-Priglinger CS, Andre S, Schoeffl H, et al: Negative regulation of RPE cell attachment by carbohydrate-dependent cell surface binding of galectin-3 and inhibition of the ERK-MAPK pathway. Biochimie 93: 477-488, 2011.

43. Shalom-Feuerstein R, Cooks T, Raz A and Kloog Y: Galectin-3 regulates a molecular switch from N-Ras to K-Ras usage in human breast carcinoma cells. Cancer Res 65: 7292-7300, 2005.
44. Boscher C and Nabi IR: Galectin-3- and phospho-caveolin1-dependent outside-in integrin signaling mediates the EGF motogenic response in mammary cancer cells. Mol Biol Cell 24: 2134-2145, 2013

45. Santiago-Gomez A, Barrasa JI, Olmo N, et al: 4F2hc-silencing impairs tumorigenicity of HeLa cells via modulation of galectin-3 and beta-catenin signaling, and MMP-2 expression. Biochim Biophys Acta 1833: 2045-2056, 2013.

46. Sant'ana JM, Chammas R, Liu FT, et al: Activation of the Wnt/beta-catenin signaling pathway during oral carcinogenesis process is not influenced by the absence of galectin-3 in mice. Anticancer Res 31: 2805-2811, 2011.

47. Dakeng S, Duangmano S, Jiratchariyakul W, et al: Inhibition of Wnt signaling by cucurbitacin B in breast cancer cells: reduction of Wnt-associated proteins and reduced translocation of galectin3-mediated beta-catenin to the nucleus. J Cell Biochem 113: 49-60, 2012.

48. Kwaan HC and McMahon B: The role of plasminogen-plasmin system in cancer. Cancer Treat Res 148: 43-66, 2009.

49. Zheng Q, Tang ZY, Xue Q, et al: Invasion and metastasis of hepatocellular carcinoma in relation to urokinase-type plasminogen activator, its receptor and inhibitor. J Cancer Res Clin Oncol 126: 641-646,2000.

50. Falasca M: PI3K/Akt signalling pathway specific inhibitors: a novel strategy to sensitize cancer cells to anti-cancer drugs. Curr Pharm Des 16: 1410-1416, 2010. 